generally is of less magnitude than that at the base of the Clent Beds. Still less did I mean to imply that the unconformity at the base of the Keuper is less, for the latter is seen to be unconformable to the Bunter in some places in the Midlands. As to whether the Clent Beds are of Carboniferous or Permian age, it is obvious that in the absence of fossils there can be no satisfactory proof. But I have always felt that the onus rests with those who link them with the Carboniferous to show good evidence for removing them from the Permian. In the Birmingham area, the distinctive composition and source of these deposits, and the pronounced unconformity at their base, seem to me to justify in the meantime their retention in the Permian.

40 OAKHIELd Road,

W. S. Boulton.

Selly Park, Birmingham. 6ih November, 1933.

\title{
ON THE PREPARATION OF GEOLOGICAL MANUSCRIPTS
}

Sir,-May I be permitted to welcome the Editor's remarks on the preparation of Geological Manuscripts and at the same time to offer a few comments.

As a palaeontologist, I am gratified to learn that " palaeontologists do seem to know their job"; still the Editor's difficulty in understanding when the name of the author of a species should be enclosed in parentheses may possibly be the fault of those writers. The rule simply is that when a species has been transferred from the genus in which its original author placed it to another genus, then, and then only, is the name of its author placed in parentheses.

Some writers make a fetish of the author's name attached to a species name. The main reason for giving it at all is to avoid confusion with possible homonyms, and it may for the same reason be necessary to give the date as well. In any case the information is helpful to a reader who may wish to look up the species. But once this information has been given, it is useless pedantry to keep repeating it throughout a paper.

The principles laid down for the use of capitals in the names of rocks, minerals, and stratigraphical divisions seem exactly to meet the case. One occasionally meets with a use of the word "carboniferous" different from any of the examples given. When a rock of any age, e.g. Miocene, contains coal, it may therefore be called a carboniferous rock, although it does not form part of the Carboniferous system.

Coming now to the method of quoting previous publications, I ask leave to draw attention to the various Reports of the British Association's Committee on Zoological Bibliography and Publication, which in this respect apply equally to palaeontology and geology.

VOL, LXX.-NO. XII. 
In general the method now proposed for the Geological Magazine agrees with that consistently recommended by the British Association Committee. An important difference, however, comes in the position of the year of publication. This the Committee considers should immediately follow the name of the author so that in any "List of papers cited", while the authors" names appear in alphabetical order, if there is more than one paper by a single author, those papers are placed in order of date, and thus are referred to without difficulty. It takes much longer to find the date of publication when it is intercalated between the volume number and the page number. Such a position is also quite illogical, and is liable to lead to confusion between "Jahrgang" and date.

It is hard to agree that the date of publication should ever be omitted, even from the "Summary of Progress of the Geological Survey". It is quite possible for a new species to be first described in the "Summary of Progress", and the precise date of its publication may be a matter of considerable importance.

One would like to suggest that in references to literature the volume number should be given in capital romans, reserving small romans for the plate numbers. The number of a series should be placed between brackets in Arabic figures before the volume number, and the number of a part, if necessary, should be placed, also in brackets, after the volume number.

It is laid down in your article that in quoting titles "capital letters should be copied exactly from the original". At one time I tried to follow this instruction, but eventually found it impracticable owing to the great diversity of treatment. It was pointed out to me that, since the capitalization of titles generally represents the fancy of the compositor, there was no virtue in following it unless one were producing a detailed bibliography in the proper sense of the word.

The abbreviations given in "Geological Literature added to the Geological Society's Library " are undoubtedly good, but attention should be drawn to the method followed in the "List of Scientific Periodicals" drawn up with the help of the British Museum. Finally, may I venture to hope that the GEological MaGazine will make the very slight modification needed to enable it to fall into line with the methods of reference recommended by the British Association Committee, and adopted by an ever-increasing number of scientific publications in all parts of the world.

\section{F. A. Bather.}

1. Dr. Bather is here referring to bibliographies, whereas the remark in the original article was intended to apply only to footnotes. The arrangement of lists of references was not discussed.--ED. 